\title{
La Universitat de València en el segle xvi. Orígens, transformacions i consolidació
}

\author{
The University of Valencia in the 16th century. \\ Origins, transformations and consolidation
}

\author{
Amparo Felipo Orts \\ amparo.felipo@uv.es \\ Universitat de València
}

\begin{abstract}
Resum. La fundació de la Universitat de València fou la culminació d'una llarga trajectòria que es remunta a la pretensió de Jaume I de conferir rang universitari a les escoles creades després de la conquesta. La seua unificació pels magistrats municipals en 1499, una butlla papal de 1500 i un privilegi regi de 1502 donaren pas a la seua inauguració oficial baix patronat municipal. Des d'ara, l'increment del pressupost universitari i les dificultats de la Ciutat per a finançar-lo va exigir la cerca de soluciones que van culminar amb la butlla de Sixte V de creació de les pabordies en 1585. Amb això, Municipi i Església passaven a sustentar conjuntament l'Estudi, no sense una interferència de la Corona de la qual van ser principal expressió les visites. En aquest context, les Constitucions de 1611 van esdevenir l'instrument de consolidació de les transformacions operades en el centre des de la seua creació.
\end{abstract}

Paraules clau. Universitat de València, butlla papal, privilegi regi, Municipi, Església, Constitucions de 1611

\begin{abstract}
The founding of the University of Valencia was the culmination of a long history that dates back to King James I's aim to give university status to the schools created after the conquest. Its consolidation drawn up by municipal magistrates in 1499, the papal bull in 1500 and the royal privilege in 1502 led to its official inauguration under the municipal board. From then on, the increase in the university's budget and the city's struggle to finance it called for new solutions, which culminated with the bull issued by Sixtus V for the creation of the pavordía chairs (title granted by the church) in 1585 . Thus, the City Council and the Church proceeded to jointly sustain the university, which was also contributed to by the Crown mainly in the form of visits. In this context, the Constitutions of 1611 formed an instrument to consolidate the transformations carried out in the centre since its creation.
\end{abstract}

Keywords. University of Valencia, papal bull, royal privilege, City Council, Church, Constitutions of 1611 
La fundació de la Universitat de València s'ha d'inscriure en el procés d'expansió universitària que va viure la Monarquia Hispànica durant bona part del segle Xvi. Però també ha d'entendre's com la culminació d'una llarga trajectòria educativa que, animada pel considerable esplendor cultural del segle xv, va encoratjar entre els magistrats valencians el desig de disposar d'un centre d'estudis que unificara les escoles creades a la ciutat des del segle xiII, En efecte, a penes conquerida València van començar a aparéixer les primeres escoles, a les quals el mateix Jaume I va voler conferir rang universitari. A la seua sol licitud en aquest sentit va respondre una butlla atorgada per Inocenci IV en 1245 concedint-li autorització per a crear un Estudi General, encara que per raons poc conegudes el projecte no va arribar a bon terme. De fet, en els furs jurats en 1261, i revisats deu anys després, el conqueridor es mostrava procliu a la llibertat d'ensenyament en atorgar que «tot clergue o altre hom puxque francament e sens tot servi e tribut tener estudi de gramàtica e de totes altres arts, e de física e de dret civil e canònich en tot loch per tota la ciutat»(Gallent 1987: 35).

Aquest fur va afavorir l'establiment a València de diverses escoles. Així, junt a la catedral, on s'ensenyava Teologia, Gramàtica i Filosofia, funcionaven centres conventuals franciscans i dominics que ensenyaven el trivium i el quadrívium, filosofia, llengües (àrab, hebreu, grec i llatí) i arts- escoles menors -encarregades de les primeres lletres-i ensenyaments particulars. Se sap que des de 1345, per mediació del bisbe Ramon Gascó, es va institucionalitzar l'ensenyament de Teologia en la Seu, sent encomanada als dominics. Des de 1424 se succeeixen notícies sobre la lectura de Poesia. També es té constància de l'inici de l'ensenyament de Cirurgia des de 1462, que s'impartiria ininterrompudament fins a la seua inclusió en l'Estudi General. Entre 1465 i 1467 Bernat Martí es va encarregar de la lectura d'Ètica, si bé manquem de notícies posteriors. Finalment, entre 1482 i 1484 Joan de Corella va ensenyar, amb càrrec al Consell, Teologia.

La dispersió d'escoles imperant va suscitar entre els magistrats municipals diferents intents d'unificar-les en un centre únic. Però la irada reacció de l'Església, poc disposada a cedir al Consell la direcció de la docència, va retardar en diverses ocasions el projecte. La primera temptativa municipal en aquest sentit data de 1373 però el bisbe Jaume d'Aragó va arribar fins i tot a decretar la presó del mestre designat per la Ciutat. La similar resposta -l'empresonament d'un mestre de la catedral- va obligar a l'adopció d'una solució pactada i a que el Consell hagués de restar a l'espera de millor ocasió. Aquesta es va presentar amb motiu de l'arribada del nou bisbe Hugo Llúpia en 1389, el qual va accedir a l'elaboració d'uns capítols tendents a la creació de la projectada escola municipal. La seua redacció es va encarregar a Pere Figuerola, mestre en Arts i Medicina, i la seua revisió a una comissió conformada per diversos juristes, metges i notaris. Però el seu contingut, com tampoc el dels articles de 1399, no ha arribat fins nosaltres. No obstant això, prova fefaent del seu abast són la sèrie de mesures que es van succeir durant els anys següents: en 1403 -tot $\mathrm{i}$ no revocar-se el principi de llibertat d'ensenyament- es va prohibir obrir escoles sense

SCRIPTA, Revista internacional de literatura i cultura medieval i moderna, núm. 15 / juny 2020 / pp. 201 - 216 ISSN: 2340-4841 · doi:/ SCRIPTA.15.17569 
l'aprovació prèvia de la Ciutat; en 1407 es va proposar l'adquisició d'un local per a albergar escoles; en 1412 va quallar definitivament la creació d'una escola municipal, que va comptar amb nous estatuts. Situada en l'edifici de Vilarragut, constava de dotze càtedres a través de les quals s'ensenyava Gramàtica, Lògica i Arts, matèries a les quals des de 1482 es va afegir Teologia (Gallent 1987: 36-37).

La culminació d'aquest procés es va produir de forma accelerada durant la dècada dels noranta: en 1492 es parla ja de la creació d'un Estudi General ; entre 1490 i 1493 es van adquirir noves cases i terres per a l'ampliació de les instal lacions, les obres de les quals van començar en 1498; finalment, el 30 d'abril de 1499 els jurats, el racional i el síndic van redactar nous estatuts per a regular el funcionament d'aquest centre. En ells, concretament en el seu article LV, contemplaven els magistrats la necessitat de sol licitar posteriorment una butlla papal i un privilegi regi que permetera conferir graus (Gallego Salvadores 1987: 39-41). Per a això, aprofitant el recent accés al pontificat del valencià Alexandre VI, els jurats van sol licitar la mediació del també valencià Joan de Vera -persona molt estimada pel pontífex, canonge de València, arquebisbe de Salern i posteriorment cardenal- a qui van facilitar les instruccions que contenien les peticions que, en nom de la Ciutat, havia de presentar al Papa.

\begin{abstract}
Item suplicarà la prefata Santedat li plàcia donar e atorgar gràcia e Bula Apostòlica en virtut de la qual la ciutat de Valencia, per ésser una de les principals e populosa del món, e sa Santedat natural de aquella, puxa eregir un Studi General, lo qual ha instituit e ja se lig de totes facultats, e per haver hi tants hòmens de sciència e de gran enteniment, tinga facultat de graduar e fer doctors, bachillers y licenciats en totes facultats. E que tinga aquella privilegis, gràcies e prerrogatives que té la ciutat de Roma, Bolunya, Salamanqua e Leyda; e que mane expedir la butla la qual ja lo cardenal de Càpua ha suplicat sa Santedat i es diu la hauria atorgada (Teixidor 1976: 160).
\end{abstract}

Finalment, el pontífex va expedir el 23 de gener de 1500 dues butlles en les quals successivament reconeixia la importància de l'erecció d'una Universitat a València i designava als seus més alts càrrecs. Tot seguit els jurats van suplicar al rei Catòlic la ratificació de l'aprovació, entregant les instruccions corresponents al síndic Joan Fenollar.

Item, per quant aquesta sua ciutat per lo benefici e augment d'aquella ha fet e construhit un Studi General en lo qual se lig de totes ciències, lo qual Studi per star afavorit y augmentat és menester que sia decorat de tots los privilegis e immunitats que ha Studi General. E així la Beatitut de nostre S. Pare ab bula sua ha atorgat e inmunit al dit Studi general ab totes les immunitats que lo Studi General de Roma, Bolunya e Salamanqua e altres tenen; per aver compliment de Studi General és menester que Sa Magestat loe e conferme la dita Bula posant hi sa Magestat Real com a cap y senyor nostre y no res menys vulla sa Real Magestat posar lo 
dit Studi General en sa protecció e salvaguarda real. E de açó suplicarà lo dit a sa Real Alteza (Teixidor 1976: 164).

Ferran II va signar el privilegi confirmatori el 16 de febrer de 1502, inaugurant-se oficialment la Universitat de València, amb tota solemnitat, el 13 d'octubre del mateix any.

Així doncs, la Universitat naix amb una forta empremta municipal que, seguint el model característic de la Corona d'Aragó, persistirà durant el seu ulterior desenvolupament, de tal manera que serà la Ciutat la que, exercint el seu patronat sobre aquesta, finance les seues despeses, designe els seus rectors i catedràtics i elabore les normes que la regeixen.

\section{El règim docent, les dificultats de finançament i la cerca de solucions}

El quadre d'ensenyaments va quedar establert ja en les Constitucions fundacionals de 1499 i va romandre vigent durant tota l'època foral. Després de passar per unes escoles on se'ls ensenyava a llegir, escriure i comptar, els estudiants, prèvia aprovació d'aquestes matèries, podien accedir als estudis de Gramàtica i Llatinitat, de caràcter bàsic. La seua conclusió permetia ingressar en les facultats d'Arts i de Lleis i Cànons. Al seu torn, acabats els estudis d'Arts i aprovat l'examen corresponent, els batxillers podien matricular-se en Teologia o Medicina.

Quant al seu finançament, els Estatuts de 1499 assenyalaven la necessitat que els estudiants contribuïren al pagament del personal de l'Estudi General mitjançant l'aplicació d'una taxa que oscil lava entre 5 i 15 sous, a la qual s'afegia la procedent de la col lació de graus.

Tot i això, de l'anàlisi de l'evolució del pressupost, determinat exclusivament pel pagament dels salaris als catedràtics, es desprén la imatge d'una Universitat caracteritzada per un procés d'expansió. En efecte, segons va constatar Gallego Barnés (1988) per al període comprés entre 1499 i 1599 i nosaltres podem perllongar fins a 1611, el pressupost universitari va mantindre una evolució ascendent derivada de la dotació de noves càtedres i dels importants increments salarials concedits a alguns dels seus titulars, segons queda reflectit en la taula i en el gràfic següents: 
Taula I

Evolució del salari de les càtedres

\begin{tabular}{|c|c|c|c|c|}
\hline & & 1499 & 1549 & 1611 \\
\hline \multirow{10}{*}{ LLATINITAT } & Llorenç Valla & - & 25 & - \\
\hline & Grec (Construcció) & - & 25 & 50 \\
\hline & Grec (Repetició) & - & - & 25 \\
\hline & Poesia & 25 & 25 & - \\
\hline & Oratòria & - & 25 & - \\
\hline & Retòrica & - & - & 200 \\
\hline & Prosòdia & - & - & 50 \\
\hline & Doctrinal Major & 15 & - & - \\
\hline & Doctrinal Menor & 15 & - & - \\
\hline & Parts & 10 & - & - \\
\hline \multirow{10}{*}{ ARTS } & Filosofia 1 & 25 & 25 & 25 \\
\hline & Filosofia 2 & 25 & 25 & 25 \\
\hline & Filosofia 3 & - & 25 & 25 \\
\hline & Filosofia 4 & - & 25 & 25 \\
\hline & Filosofia 5 & - & 25 & 25 \\
\hline & Filosofia 6 & - & 25 & 25 \\
\hline & Filosofia Moral & 25 & 25 & 25 \\
\hline & Metafísica & - & - & 50 \\
\hline & Astrologia & - & 25 & 100 \\
\hline & Matemàtiques & - & - & - \\
\hline \multirow{8}{*}{ MEDICINA } & Curs 1 & 25 & 25 & 75 \\
\hline & Curs 2 & - & 25 & 75 \\
\hline & Curs 3 & - & - & 75 \\
\hline & Aforismes & - & - & 90 \\
\hline & Anatomia & - & - & 75 \\
\hline & Herbes i Simples & - & - & 125 \\
\hline & Mètode & - & - & 100 \\
\hline & Cirurgia & - & 15 & 60 \\
\hline \multirow{9}{*}{ TEOLOGIA } & Sant Tomàs 1 & - & 25 & 100 \\
\hline & Sant Tomàs 2 & - & - & 50 \\
\hline & Sentències & - & - & 100 \\
\hline & Testament Vell & - & 25 & - \\
\hline & Sagrada Escriptura & 25 & 50 & - \\
\hline & Durando & - & 25 & - \\
\hline & Teologia & 25 & 50 & - \\
\hline & Hebreu (Construcció) & - & 25 & 50 \\
\hline & Hebreu (Repetició) & - & - & 25 \\
\hline \multirow{3}{*}{ DRET } & Instituta & - & - & 100 \\
\hline & Dret Canònic & 25 & 25 & 150 \\
\hline & Dret Civil & 25 & 25 & 130 \\
\hline
\end{tabular}

Font: Felipo Orts, A. (1991). Elaboració pròpia 


\section{Gràfic I}

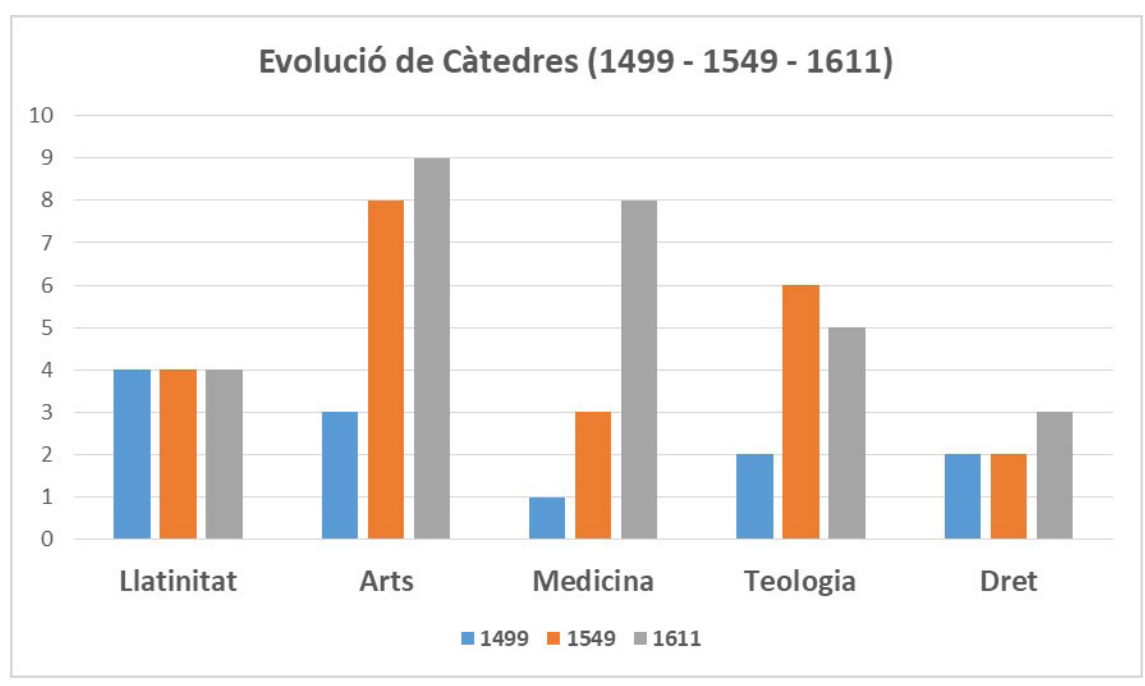

Font: Felipo Orts, A. (1991). Elaboració pròpia

En ells, per damunt de les diferències entre facultats, marcades tant pel nombre de càtedres proveïdes com per les modificacions salarials, s'adverteix un considerable i progressiu increment del pressupost, que assoleix el seu punt culminant en 1611, com veiem en el gràfic II.

\section{Gràfic II}

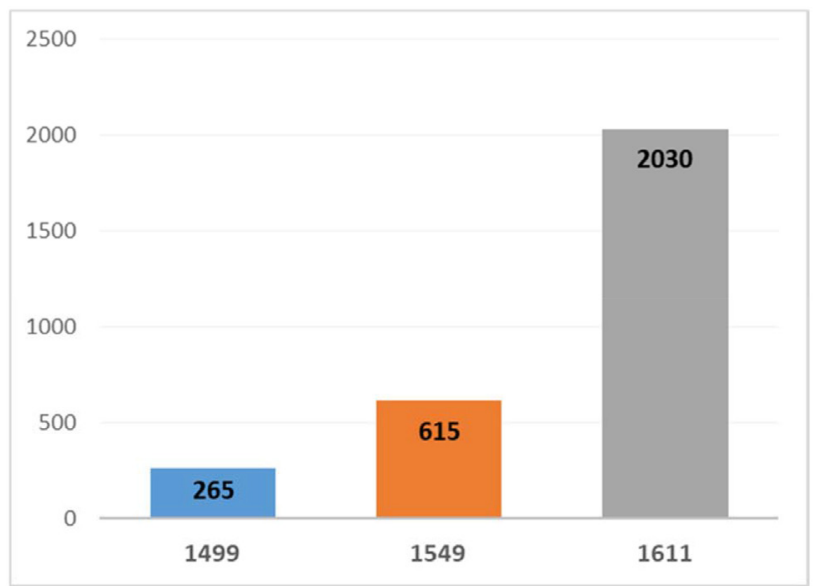

Font: Felipo Orts, A. (1991). Elaboració pròpia 
L'evident increment de la despesa generada per la Universitat no va poder menys que provocar dificultats econòmiques al Municipi per a afrontar-lo, que es van aguditzar en moments de crisis, i davant les quals va ser necessària l'adopció de successives mesures per a pal liar-les, com ara l'intent que la duquessa de Calàbria subvencionara l'Estudi, l'emissió de censos, l'obtenció de la butlla de 1564 i la unió de la pabordia de febrer.

Amb tot, el primer punt d'inflexió cal situar-lo en el context del moviment agermanat, de greus conseqüències per a la vida universitària donat que la Ciutat, exhausta, no va poder fer front als salaris de les càtedres i es va veure obligada a decretar el tancament de les aules a l'octubre de 1522. Tot i que la normalitat acadèmica es va restablir al maig de 1523, la deteriorada situació econòmica de les arques municipals va persistir durant els anys següents. De fet, encara al mes de març de 1528 qui aleshores era rector, Joan de Celaya, en un intent d'afrontar aquesta situació, va fer pública la concessió d'indulgència plenària als qui contribuïren a sustentar la Universitat, però la mesura no va produir els resultats desitjats (Felipo 1993: 56-59).

En aquesta mateixa línia cal situar el projecte de la duquessa de Calàbria de subvencionar l'Estudi General. Animada pel cercle d'humanistes que es reunia el seu voltant, en 1544 donya Mencía de Mendoza va comunicar als magistrats la pretensió de dotar a la Universitat amb una renda perpètua suficient per a cobrir els salaris dels catedràtics. La idea va ser acollida de bon grat i seguida de la celebració de diferents reunions entre totes dues parts, que van culminar amb la redacció de les anomenades Capitulacions de la duquessa de Caläbria, que estipulaven les condicions en què s'havia de procedir al finançament. Encara que alguns autors han volgut veure en això un possible desig d'erigir un col legi trilingüe a imitació del que funcionava a Alcalá, en realitat, el projecte resultava molt més ambiciós. Es tractava ni més ni menys que de la transferència a donya Mencía del patronat sobre la Universitat, que fins a eixe moment ostentava el Municipi.

En efecte, a canvi de la dotació d'una renda perpètua, la duquessa es reservava el control absolut sobre el centre, en quedar al seu criteri la redacció de nous estatuts, la provisió de càtedres, la designació de catedràtics i l'elecció dels autors a seguir, amb l'únic compromís de mantenir totes les Facultats existents. Per part de donya Mencía, l'assumpció d’un projecte tan costós, que, a més de la dotació de la renda perpètua, comportava la creació d'un col legi annex i la construcció d'un edifici nou, constituïa una iniciativa que bé podria relacionar-se amb altres similars protagonitzades coetàniament per mecenes d'origen nobiliari en un moment de plena expansió universitària. Però, malgrat la minuciositat amb què s'havia treballat en l'elaboració dels articles i l'il lusionat acolliment que havien tingut entre els sectors humanistes, finalment les capitulacions no van arribar a implantar-se perquè tant donya Mencía com els jurats van renunciar a elles al maig de 1548. Encara que posteriorment el Consell va atorgar poder als jurats perquè iniciaren noves negociacions amb la duquessa de Calàbria, la seua defunció en 1554 va posar fi a aquesta pretensió (Felipo 1998: 141-154).

Per tant, en els anys següents el Municipi va haver de continuar fent front a les despeses recorrent, amb la finalitat d'ajudar-se, a l'emissió de censos. L'origen d'aquests, encara que puga semblar 
contradictori, cal situar-lo en els préstecs concedits per l'Estudi a determinades persones o institucions a partir de les sumes que, encara que no administrava, atresorava, com eren les procedents de les propines dels graus. A més, una butlla atorgada en 1564 per Pius IV va intentar alleugerir la precarietat salarial dels catedràtics mitjançant la distribució entre ells de 500 ducats anuals procedents de la Mensa Episcopal d'Oriola (Felipo 1993: 60-61).

Però totes les solucions esmentades es van mostrar minses per a millorar la situació, sobretot en moments de màximes dificultats com les que es van viure durant la dècada dels huitanta (Miralles1985: 111-125). Per a esmenar-les, en aquesta ocasió els jurats van pensar en la unió de la pabordia de febrer, destinant tres parts de la seua renda a la Universitat i la resta a l'Hospital General. A tal fi, el 31 de maig de 1582 van acordar sol licitar-la de don Tomás de Borja al qual van concedir a canvi 12.000 lliures. La negociació, encarregada al Maestre de Montesa, va durar diversos anys i va comptar amb el suport de don Joan de Ribera, arquebisbe de València, del rei i del Papa. En aquest sentit es conserva una carta dels jurats sol licitant l'ajuda del primer, i una altra demanant al monarca la seua intercessió davant el pontífex. Finalment, una butlla de 1585 signada pel papa Sixte V creava a càrrec de les rendes decimals de la pabordia de febrer díhuit càtedres, que en funció del seu origen es van denominar càtedres pabordies. Però caldria esperar fins al 23 de juny de 1588 perquè foren nomenats els primers quatre pabordes de Teologia, dotant-se les places restants en 1589.

Amb això, de moment s'esperaven solucionar els problemes econòmics. No obstant, la mesura no va tindre els resultats abellits. Els salaris, de per si mateix elevats, van ser sotmesos en poc temps a successius augments. Aquests increments, juntament amb els desemborsaments derivats dels nombrosos plets promoguts, van impedir que la Ciutat es recuperara ràpidament de les despeses de l'obtenció de la renda en favor de la Universitat i de les del plet amb dels canonges. Això va donar peu a que progressivament acabaren deixant-se de dotar moltes de les pabordies (Felipo-Callado, 2016: 19-28).

Amb tot, és necessari assenyalar que, independentment de la creació de les prepositures, la suma global dels salaris de l'Estudi va continuar la seua progressió ascendent en favor de la resta de les facultats. Per aquest motiu els problemes de finançament persistiren, exigint l'adopció d'altres solucions durant el segle XVII, consistents fonamentalment en l'aplicació de noves cises i en la constitució de censos. D’altra banda, la dotació de les pabordies va suposar que el salari d'una part de les càtedres de Teologia i Dret correria per compte de l'Església Metropolitana València. A canvi, el càrrec de rector recauria invariablement en un canonge o dignitat d'aquesta, situació que es mantindria fins a finals del segle XVIII. Per tant, d'ara en avant Municipi i Església sustentarien conjuntament la Universitat. 


\section{La interferència reial. Les visites a l'Estudi General}

Ara bé, aquesta forta vinculació de l'Estudi General al Municipi i a l'Església no va impedir que es produïra també una marcada interferència de la Corona. Aquest fenomen, comú a la major part de les universitats espanyoles durant l'època moderna, va tindre la seua principal expressió en la de València en l'enviament de dos visitadors successius per Felip II, en els dos casos en estreta relació amb els propòsits reformistes del Patriarca Ribera.

Joan de Ribera va arribar a València en 1569 i la seua primera gran empresa va ser precisament un projecte de reforma de la Universitat que permetera als estudiants oir Teologia en el Col legi de Sant Pau de la Companyia de Jesús, creat a penes feia dos anys (Robres 1969:122). No obstant això, les pretensions del Patriarca, favorables als jesuïtes xocaven amb els Estatuts universitaris i amb el patronat municipal. Els orígens del problema cal situar-los en els privilegis papals atorgats a la Companyia de Jesús de poder impartir títols acadèmics, en la posterior obertura del Col legi de sant Pau en 1567 i en els enfrontaments entre els jesuïtes i els magistrats municipals, derivats de la prohibició, recollida en les Constitucions de 1561, que els estudiants de la Universitat cursaren lliçons fora d'ella (Robres 1969:139).

En tan delicada conjuntura, el favor dispensat per l'arquebisbe a la Companyia de Jesús va fer esclatar les tensions el mateix any de la seua arribada, quan el Patriarca va decidir intervindre en l'Estudi, esgrimint com més ferma justificació el decret del Concili de Trento que es pronunciava sobre la necessitat de revisar les condicions dels ensenyaments. Amb això, el conflicte no havia fet sinó començar perquè, depassant àmpliament l'àmbit acadèmic, aquest immediatament va adquirir connotacions polític-socials derivades de la intervenció del monarca, el Consell d'Aragó, la Inquisició, el Municipi, o fins i tot de la divergència de l'Església, la presa de posicions de la noblesa, els catedràtics de la Universitat i els estudiants, fins al punt d'alterar la normalitat ciutadana (García Martínez 1985: 3-50).

Així les coses, la proposta que al gener de 1570 va elevar Ribera al Consell d'Aragó denunciant la prohibició als estudiants d'oir Teologia en centres religiosos i defensant la necessitat de reforma de la Universitat, va culminar amb la comissió per a la realització de la inspecció atorgada per Felip II al propi arquebisbe, que es va convertir així en jutge i part d'una qüestió en la qual estava tan vivament interessat. A això encara cal afegir que l'encàrrec de la visita, atorgat a Còrdova el 31 de març de $1570^{1}$ conferia a Ribera, en la seua doble condició d'arquebisbe de València i canceller de la Universitat, poders molt amplis a l'aplicació dels quals no va renunciar, si s'ha de jutjar per la immediata oposició que el contingut dels seus apuntamientos va suscitar entre els magistrats municipals.

En aquestes circumstàncies, la inspecció va adquirir dimensions totalment imprevisibles, els detalls de les quals, estudiats des de perspectives diferents i complementàries per Ramón Robres, García

1 AMV. Cartas reales, h3-5, fols. 184-186.

SCRIPTA, Revista internacional de literatura i cultura medieval i moderna, núm. 15 / juny 2020 / pp. 201 - 216 ISSN: 2340-4841 · doi:/ SCRIPTA.15.17569 
Cárcel, Antonio Mestre, Sebastián García i Rafael Benítez, es van desenvolupar en dos àmbits: el Sant Ofici, després de la denúncia de la difusió de pasquins infamatoris contra el prelat, que va comportar l'empresonament i procés del rector Monzó i dels catedràtics de Teologia Luviela, Mijavila i Cavaller (García Cárcel 1980: 62-69); i el extra inquisitorial, que va tindre com a manifestacions més reeixides la destitució il legal del rector imposada pel Patriarca o el fracassat intent de Felip II de resoldre el conflicte mitjançant l'avinença de les parts implicades. A aquest efecte, en missiva de 8 de setembre de 1570, el Rei Prudent, al mateix temps que comunicava als jurats la conclusió de la visita pel prelat els indicava la conveniència de designar representants de cada part que permeteren arribar a una eixida de compromís. ${ }^{2}$ Però la solució al conflicte entre l'arquebisbe i la Ciutat encara tardaria a arribar, simplement perquè era obvi que cap dels sectors involucrats tenia intenció de cedir.

És per això que, davant els resultats de la visita i els esdeveniments posteriors, es pregunta Robres si no pot concloure's que es va tractar d'una reforma fallida, i ell mateix respon que «los catedráticos que el reformador hubiera querido eliminar, terminado el proceso, volvieron a sus lugares» i que això fou així perquè «Luviela, Mijavila, Monçó, Blay Navarro... tenían el favor de la ciudad y seguramente Felipe II no se atrevió a excitar más los ánimos» (Robres 1969: 168). La connivència entre els catedràtics i la Ciutat és també destacada per Rafael Benítez qui, a partir de l'anàlisi dels informes enviats per Ribera a la Inquisició, observa que, segons ell mateix anotava, per al Patriarca l’agitació ciutadana va estar motivada per les intrigues dels catedràtics (Benítez 1990: 323).

En canvi, Antonio Mestre sembla restar protagonisme als catedràtics en concloure que « uno no puede escapar a la impresión de que los representantes de la ciudad mueven los hilos desde sus sillones municipales, mientras los profesores y, en consecuencia, los clérigos y estudiantes que participaron en el asunto de los pasquines dan la cara en público»; i fins i tot unes pàgines després afirma: «Todos los personajes, desde el rector Pedro Monzón al estudiante José Esteve fueron totalmente secundarios y, bien mirado, instrumentos manejados por la oligarquía municipal» (Mestre, 1981: 31-35). En tot cas, foren els qui foren els promotors, el que sembla clar és que, com referia Sebastián García, les relacions entre la Ciutat i l'Estudi es van estrényer encara més després de la crisi i que els magistrats municipals van assegurar la promoció dels catedràtics adversaris de Ribera, mentre ells van continuar exercint les funcions que, en exercici del patronat municipal, els competien (García Martínez 1985: 42-43). D'aquesta manera el primer projecte de reforma hauria culminat amb el fracàs de l'arquebisbe.

Malgrat tot, Ribera va continuar en anys posteriors tractant de fer realitat les seues intencions. I en aquest context, la creació de les pabordies baix control municipal en 1585 va actuar com a argument d'un nou episodi d'un antic conflicte no resolt. El seu contingut va suscitar la immediata oposició de diferents sectors, i molt particularment del capítol de canonges, poc inclinats a qualsevol concessió als pabordes que poguera lesionar la seua primacia. Referent a això, ja en missiva de

2AHN. Consejos, 2381, fol. 151.

SCRIPTA, Revista internacional de literatura i cultura medieval i moderna, núm. 15 / juny 2020 / pp. 201 - 216 ISSN: 2340-4841 · doi:/ SCRIPTA.15.17569 
3 d'octubre de 1587 Felip II feia arribar al seu ambaixador a Roma la denúncia dels jurats de València relativa al fet que, malgrat la concessió pontifícia de la supressió de la pabordia, moguts per interessos particulars, el capítol i canonges de l'Església tractaven d'entorpir la seua consecució. Quan superats els primers obstacles es va intentar posar en execució el contingut del document papal, el capítol de canonges, argüint els perjudicis que derivarien d'aquest, va manifestar la seua més decidida oposició, no dubtant a sol licitar la intercessió del virrei i fins i tot a recórrer davant la Real Audiència.

Aquesta actitud va provocar, d'una banda, la ràpida reacció dels jurats els qui, en carta de 28 de juny de 1588, van sol licitar la mediació de Ribera davant els canonges perquè desistiren en la seua obstinació d'impedir la dotació de les pabordies, però també la del Papa i la del monarca. Per una altra, la simultània actuació del jutge apostòlic delegat per a l'execució de la butlla, qui va posar en dubte al capítol, va excomunicar a alguns canonges, va donar possessió als pabordes designats per la Ciutat i els va atorgar seient en el cor, insígnies canonicals i les preeminències estipulades. Per part seua, el Papa amb la finalitat de resoldre el conflicte va publicar un Breu datat el 12 d'octubre de 1588, que va afavorir el momentani apaivagament de les dissensions (Crespí de Borja 1641: $57-$ 63).

Però el parèntesi va ser breu. El reviscolament de l'enfrontament entre canonges i pabordes va arribar a tal extrem que va obligar l'arquebisbe Ribera a dictar un decret en 1596. En ell la relegació dels pabordes enfront dels canonges per part del prelat és evident- quedant-los totalment prohibit ocupar qualsevol seient que precedira al dels canonges- $\mathrm{i}$ la pena pel trencament de la disposició tan contundent com l'excomunió. En tot cas, la rotunditat del contingut del mandat va resultar decisiva en la consecució de l'objectiu de paralitzar els plets, sobre els quals es va enviar comissió a la Rota, si bé és cert que aquests no tardarien a reproduir-se.

I potser no van ser del tot alienes a això les circumstàncies que van acompanyar a la visita de la Universitat duta a terme entre 1598 i 1599, que va contribuir en gran manera a avivar la polèmica sobre les pabordies. Perseverantment reclamada per Ribera després del seu fracassat projecte de reforma de l'Estudi General en la dècada dels setanta, les primeres notícies de què disposem sobre la pretensió d'una nova inspecció procedeixen del mes d'abril de 1595 i responen a una petició conjunta de l'arquebisbe i del virrei, marqués de Dénia. ${ }^{3}$ En la base d'aquesta nova sol licitud sembla situar-se la conjuntura propícia que oferia la negativa del rector de proveir la vacant de la pabordia primària de Teologia, produïda per la mort del conegut Jaume Ferruz al desembre de 1594, el subsegüent plet iniciat pels magistrats municipals contra el rector i l'acord municipal de redactar nous estatuts. No obstant això, la resolució definitiva es va veure dilatada per la disconformitat del monarca amb els successius personatges proposats per a aquesta missió. ${ }^{4}$

3 ACA. CA. Leg.652, doc. 5/2.

4ACA. CA. Leg.652, doc. 5/4.

SCRIPTA, Revista internacional de literatura i cultura medieval i moderna, núm. 15 / juny 2020 / pp. 201 - 216 ISSN: 2340-4841 · doi:/ SCRIPTA.15.17569 
Això va comportar la demora de la visita. Però, contràriament a l'actitud real, els magistrats municipals es van mostrar molt diligents en la redacció de nous estatuts i potser encara més el Patriarca Ribera a elevar al Consell d'Aragó un memorial, datat el 30 de juny de 1595, exposant les que considerava irregularitats del seu contingut -entre elles el que qualificava de favoritisme amb què els jurats pensaven proveir la vacant de la pabordia, que finalment es faria recaure en un antic adversari del Patriarca com Pere Monzó, la qual cosa sens dubte condicionaria la posició del prelat-, que, una vegada més, va aprofitar aquesta circumstància per a denunciar les deficiències de la Universitat i la urgència de sotmetre-la a una nova visita. I en el mateix sentit es pronunciaria en les constants i reiteratives missives dirigides al Rei Prudent durant els mesos següents.

Tanta insistència va determinar que finalment el monarca sol licitara al virrei i al mateix Ribera que proposaren persones capacitades per a afrontar la inspecció de l'Estudi. No obstant això, la lentitud en la presa d'una resolució pel monarca indueix a pensar en el seu desig d'ajornar l'assumpte i de no participar, almenys de manera immediata, en el que s'intueix com una pugna entre les institucions delegades de la Corona -arquebisbe, virrei i Consell d'Aragó-, d'una banda, i l'oligarquia municipal, per una altra. Així semblen confirmar-ho la consulta elevada pel Consell d'Aragó al març de 1596, així com una nova carta del virrei, marqués de Dénia, de maig del mateix any. I encara sembla corroborar més aquesta opinió el fet que el Consell d'Aragó haguera d'apel lar, una vegada més, al juny de 1596, a la manca de la inspecció, que compartia amb el virrei i amb l'arquebisbe, assegurant que

\begin{abstract}
En otras consultas que no están resueltas ha representado a Vuestra Magestad el Consejo que ay necesidad precissa de que se visite la Universidad de la ciudad de Valencia, moviéndose a ello por lo que el marqués de Denia y el Patriarca han escrito en diferentes cartas. Y también porque por otras vías se ha entendido ser tan necesario, como el marqués y el Patriarca lo escriben. ${ }^{5}$
\end{abstract}

I tampoc deixa de resultar simptomàtic que, en aquesta conjuntura, el bisbe de Segorbe, a qui finalment s'havia encomanat, excusara la realització de la visita al legant problemes de salut però, sobretot que «al Patriarca, que la quiso visitar, le dieron las pesadumbres que Vuestra Magestad sabe y lo hubo de dexar». ${ }^{6}$ Així doncs, el bisbe de Segorbe, coneixedor de la dificultat que comportava la visita, conscient de la pretensió de la Ciutat de mantindre a ultrança el patronat sobre la Universitat i també del fracàs assolit per Ribera en el seu intent de modificació d'aquesta situació, va preferir quedar al marge.

Seria finalment en don Alonso Coloma, capellà real i canonge de la magistral de Sevilla, sobre qui recaiguera l'encàrrec el mes d'abril de 1598 (Seguí, 1992). És precisament la missiva dirigida pel

5 ACA. CA. Leg. 606, doc. 3/4.

6 ACA. CA. Leg. 606, doc. 3/6.

SCRIPTA, Revista internacional de literatura i cultura medieval i moderna, núm. 15 / juny 2020 / pp. 201 - 216 ISSN: 2340-4841 · doi:/ SCRIPTA.15.17569 
monarca al rector i catedràtics de la Universitat la que evidencia l'estreta relació entre la comesa a Coloma i la necessitat de posar fi als nombrosos problemes suscitats per l'erecció de les pabordies. I així ho constaten també les instruccions que acompanyaven a la comissió per a la visita, datada el 14 d'abril de $1598 .^{7}$ A penes arribat a València, Coloma es va afanyar a atendre en primer lloc les qüestions relacionades amb la dotació de les pabordies, de les quals, des del primer moment, va estimar especialment perniciosa l'exigència que el rector fora un canonge de la Seu. Així es desprén de la carta que, en resposta a un dels seus informes, li remetia el príncep Felip des de l'Escorial al juliol de 1598 aconsellant-li posposar l'atenció a aquest tema per al final de la visita. En aquesta mateixa línia cal inscriure la carta al virrei, comte de Benavente, perquè, tractant-ho prèviament amb els jurats, procurara que no es realitzara elecció de nou rector fins a haver conclòs la visita. ${ }^{8}$

Entretant, Coloma continuava la inspecció i ja el mes de gener de 1599 estava en condicions de presentar el seu informe, postergant l'atenció dels restants assumptes a la resolució d'aquest (Febrer 2000: 152-154). En ell el visitador feia recaure gran part de la responsabilitat del mal funcionament de l'Estudi sobre dos tipus de conseqüències derivades de l'erecció de les pabordies: d'una banda, l'excessiu número de les mateixes $i$, per una altra, l'exigència que el càrrec de rector recaiguera sobre un canonge de la Seu (Seguí 1992: 337-346). Sotmesos els resultats de la seua investigació a la consideració dels jurats, aquests van acceptar, respecte al nomenament del rector, suplicar al Papa la concessió de plena autoritat per a designar lliurement a qualsevol doctor o llicenciat de la Universitat, amb independència que reunira o no la condició de canonge de la Seu, al mateix temps que van defensar la necessitat de mantindre almenys quatre pabordies, la provisió de les quals també els competira. No obstant això, aquests acords no van tenir efecte algun. ${ }^{9}$

Per tant, els problemes pendents respecte a la conveniència de la provisió de les pabordies van romandre latents, manifestant-se obertament en 1604, en obstaculitzar el virrei, comte de Villamizar, la provisió de tres prepositures de Cànons, Lleis i Teologia. De la documentació es desprén que també en aquesta ocasió el virrei actuava en col laboració amb els canonges i el capítol de la Seu, als qui el síndic de la Ciutat acusava de tractar d'impedir l'execució de la butlla com a mitjà d'incrementar els seus ingressos, qualificant d'injusta l'actitud adoptada pels canonges davant la concessió que els pabordes pogueren portar insígnies.

L'acusació al capítol i als canonges no pot ser més directa. I és que en la dotació de les pabordies els canonges no sols percebien la competència que suposaven les preeminències que els pabordes pogueren adquirir sinó el menyscapte d'una renda de la qual anteriorment havien gaudit. En el sector oposat, cal situar el temor de la Ciutat a la pèrdua del patronat municipal puix que estimava que, com ja havien intentat anteriorment, els canonges pretendrien exercir-lo sobre la pabordia de

\footnotetext{
7 AHN. Consejos, 2397, fols. 148v-149.

8 AHN. Consejos, 2397, fols. 220-220v.

9ACA. CA. Leg. 866, doc. 114.
}

SCRIPTA, Revista internacional de literatura i cultura medieval i moderna, núm. 15 / juny 2020 / pp. 201 - 216 ISSN: 2340-4841 · doi:/ SCRIPTA.15.17569 
febrer. Per això els magistrats sol licitaven al rei que els permetera continuar exercint-lo lliurement com a mitjà d'aconseguir importants fruits.

En aquesta conjuntura, la mediació de Felip III en 1605 no va constituir més que un breu parèntesi perquè, en realitat, no va posar fi al conflicte (Felipo 2012: 400) .

És possiblement aquest el context en el qual cal situar la que, potser, fou l'última i desesperada sol licitud del Patriarca Ribera al monarca, datada el 22 de juliol de 1606, que ordenara una nova visita com a mitjà de frenar el que qualificava de progressiu deteriorament de la Universitat. Aquest és un extracte del seu contingut

\begin{abstract}
Sacra Cesarea Real Magestad. Muchos años ha que se dessea en este Reyno por las personas de buen zelo el redreço y reformación del Estudio General de Valencia el qual, aviendo sido de los más bien reputados de toda España y aún excedídoles en algunas facultades, se ha ydo deteriorando de manera que se conoçe muy bien la extrema necessidad que tiene de que se pongan en execución las cosas que son necessarias para formar y conservar una buena Universidad. El rey nuestro señor, que está en el cielo, teniendo noticia desto, y movido de su santo zelo, me mandó treynta y seys años ha que me ocupasse en reformar este Estudio. Y aunque hize de mi parte lo que supe, y el Consejo Supremo de Aragón mostró tener satisfación de los papeles que imbié aprovándolos, no tuvo effecto la reforma, ni tampoco la ha tenido la visita que después hizo don Alonso Coloma. Y assí ha quedado la Universidad con la misma necessidad della que antes, y aún con mayor, porque cada día se va reduziendo a peor estado. Todo lo qual, y ser annexo a esta dignidad el officio de canceller, me obliga a supplicar a Vuestra Magestad, como lo hago humilmente, sea servido de mandar visitar estas escuelas... Con lo qual no sólo hará Vuestra Magestad grandíssimo bien a este su Reyno, y aun a todos los de España, pero descargará su real consciencia. ${ }^{10}$
\end{abstract}

Res sabem sobre els resultats immediats de la seua demanda però, en tot cas, convé recalcar que Ribera no va desistir de la seua pretensió de reforma de l'Estudi fins al final dels seus dies, tot i que no li van reportar els resultats desitjats. És més, a penes quatre mesos després de la seua mort es van promulgar les noves Constitucions de 1611 que no sols no van introduir canvis substancials respecte a l'anterior funcionament del centre, sinó que van sancionar l'íntima relació entre la Universitat i el Municipi. A més, recollint les transformacions operades en l'Estudi des de la seua creació, van conservar la seua vigència fins a finals del segle XvIII, esdevenint així en un instrument de consolidació de l'estatus universitari assolit.

10 ACA. CA, Leg.866, doc.114. 


\section{Bibliografia}

Benítez Sánchez-Blanco, R. (1990) «El Patriarca Ribera y la Inquisición ante el conflicto universitario», Homenaje a D. Ignacio Valls, Valencia, Facultad de Teología San Vicente Ferrer, pp. 321-349.

Crespí de Borja, L. (1641) Origen y progreso de las pavordías de la Santa Metropolitana Iglesia de Valencia. Roma.

Febrer Romaguera, M. V. (2000) «Motines, excomuniones y visita real en el Estudio de Valencia: 1593-1599» en Las Universidades Hispánicas. De la Monarquía de los Austrias al Centralismo liberal, vol. I, Salamannca, Universidad de Salamanca, pp. 141-163.

Felipo Orts, A. (1991) La Universidad de Valencia durante el siglo XVII (1611-1707), València Generalitat Valenciana, Conselleria de Cultura, Educació i Ciència.

- (1993) La Universidad de Valencia durante el siglo XVI (1499-1611), València, Universitat de València.

- - (1998) «El proyecto universitario de doña Mencía de Mendoza. Las capitulaciones de 1544», Doctores y Escolares, vol. 1. València, Universitat de València, pp. 141-154.

(2012) «El patriarca Ribera, las pavordías y los proyectos de reforma de la Universidad de Valencia», E, Callado Estela, M. Navarro Sorní (coords) El patriarca Ribera y su tiempo: religión, cultura y política en la Edad Moderna, Valencia, Institució Alfons el Magnànim, pp. 385-404.

Felipo Orts, A. \& Callado Estela, E. (2016) Entre la cátedra y el púlpito los pavordes de la Universidad de Valencia (siglos ХИл-ХИІі), Valencia, Universitat de València.

Gallego Barnés, A. (1988) «El presupuesto del Studi General durante el siglo XVII», Homenatge al doctor Sebastià Garcia Martínez, Valencia, Generalitat Valenciana- Universitat de València, vol. 2, pp. 75-84.

Gallego Salvadores, J. (1987) «La creación pontifícia y real», Universidades valencianas, Valencia, Generalitat Valenciana, pp. 39-45.

Gallent Marco, M. (1987) «Los estudios medievales», Universidades valencianas. Valencia, Generalitat Valenciana pp. 35-38.

García Cárcel, R. (1980) Herejía y sociedad en el siglo ХVI. La Inquisición en Valencia (1530-1609), Barcelona, Ed. Península.

García Martínez, S. (1985) «San Juan de Ribera y la primera cuestión universitaria (1569-1572)», Contrastes, Revista de Historia Moderna, vol. I, pp. 3-50.

Mestre Sanchis, A. (1981) «Jerarquía católica y oligarquía municipal ante el control de la Universidad de Valencia (el Obispo Esteve y la cuestión de los pasquines contra el Patriarca Ribera)», Anales de la Universidad de Alicante. Historia Moderna, nº 1, pp. 9-37.

Miralles Vives, F. (1985) «Nuevos documentos para la historia de la Universidad de Valencia. Los desórdenes de 1580-90», Saitabi, XXXV, pp. 111-125.

SCRIPTA, Revista internacional de literatura i cultura medieval i moderna, núm. 15 / juny 2020 / pp. 201 - 216 
Amparo Felipo Orts. La Universitat de València: Orígens, transformació i consolidació

Robres, R. (1969) San Juan de Ribera, Patriarca de Antioquía, arzobispo y virrey de Valencia, 1533-1611. Un obispo según el ideal de Trento, Barcelona, Ed. Juan Flors.

Seguí Cantos, J. (1992) «El memorial de don Alonso Coloma en su visita a la Universidad de Valencia (1598-1599)», Hispania, vol. LII/1 (180), pp. 337-346.

Teixidor y Trilles, J. (1976) Estudios de Valencia (Historia de la Universidad hasta 1616). Introducción, índices y notas por Laureano Robles. Valencia, Universitat de València.

SCRIPTA, Revista internacional de literatura i cultura medieval i moderna, núm. 15 / juny 2020 / pp. 201 - 216 ISSN: 2340-4841 · doi:/ SCRIPTA.15.17569 